\title{
Five zinc finger protein 350 single nucleotide polymorphisms and the risks of breast cancer: a meta-analysis
}

\author{
Yu Fan Zeng ${ }^{1}$ and Jianfeng Sang ${ }^{2}$ \\ ${ }^{1}$ From the Bachelor of Health Sciences, McMaster University, Hamilton, Ontario, Canada \\ ${ }^{2}$ Department of General Surgery, Nanjing Drum Tower Hospital, Nanjing, China \\ Correspondence to: Jianfeng Sang, email: glyy8c@163.com \\ Keywords: breast cancer, meta-analysis, SNP, ZNF350, DNA damage
}

Received: June 01, $2017 \quad$ Accepted: August 04, $2017 \quad$ Published: October 07, 2017

Copyright: Zeng et al. This is an open-access article distributed under the terms of the Creative Commons Attribution License 3.0 (CC BY 3.0), which permits unrestricted use, distribution, and reproduction in any medium, provided the original author and source are credited.

\section{ABSTRACT}

Some studies have reported an association between the zinc-finger protein $\mathbf{3 5 0}$ (ZNF350), also known as zinc-finger and BRCA1-interacting protein with a Kruppelassociated box (KRAB) domain (ZBRK1), and risks of breast cancer, although the results remain controversial. A systematic search was conducted on PubMed, Web of Science, EMBASE, Ovid, Chinese National Knowledge Databases, and WanFang databases with relevant keywords. Four studies of five distinct populations involving 5824 breast cancer cases were used to conduct a meta-analysis that summarizes the current evidence of 5 genetic polymorphisms: Asp35Asp, Leu66Pro, Pro373Pro, Ser472Pro, and Ser501Arg in the ZNF350 gene. The T allele in Asp35Asp polymorphisms not significantly associated with increased risk of breast cancer (OR: $1.08 ; 95 \%$ CI: 0.96-1.21). The minor C allele of the Asp35Asp polymorphism is protective in the overdominant model (OR $=1.14 ; 95 \% \mathrm{CI}: 1.02-1.28)$. The Pro allele in the Leu66Pro polymorphism is protective in all of the models examined (allelic, dominant, recessive, and overdominant). The Pro373Pro is not associated with breast cancer in all of the models tested. The Pro allele of the Ser472Pro polymorphism is protective using the dominant model $(O R=0.10 ; 95 \% \mathrm{CI}: 0.04-0.23)$ but deleterious using the overdominant model (OR = 1.14; 95\% CI: 1.02-1.28). The Ser501Arg polymorphism is deleterious only when using the recessive model (OR $=1.21 ; 95 \%$ CI: 1.02-1.44). In conclusion, this meta-analysis suggests that genetic polymorphisms in the ZNF350 variant can increase, decrease, or have no effect on the risks of breast cancer depending on the polymorphism and genetic model used. Further studies will be required to validate these findings.

\section{INTRODUCTION}

Breast cancer is the most common malignancy in women worldwide [1] and leads to $15 \%$ of all cancerrelated deaths in women [2]. In western countries, the lifetime risk of developing breast cancer can be as high as 1 in 8 in women [3], resulting in a substantial burden to global health care.

Although the exact pathogenic mechanism of breast cancer remains elusive, polygenic models assuming a multiplicative effect on suggest that near $50 \%$ if all breast cancer cases fall within $12 \%$ of the population with increased risks of breast cancer $[4,5]$. Thus, investigating the genetic factors playing roles in the development of breast cancer could not only aid in the search for pathological mechanism, but also have important influences on breast cancer screening and prevention.

Mutations in the tumour suppressor gene breast cancer 1 (BRCA1) accounts for almost 50\% hereditary breast cancer [6] and reduced BRCA1 expression strongly correlated with accelerate growth and progression of sporadic breast cancer [7]. BRCA1 encodes a $220 \mathrm{kDa}$ nuclear protein that is heavily involved in DNA damage repair, transcriptional regulation, and cell cycle checkpoint $[8,9]$. Mutations in BRCA1 often leads to genomic instability [10]. It has been shown that BRCA1 recruits 
the DNA/RNA helicase Senataxin to resolve R-loops often found at transcriptional terminators and prevents R-loop accumulation-driven DNA damage [11].

The C-terminus of BRCA1 acts as an transcriptional activator to cell-cycle regulated genes such as growth arrest and DNA damage gene $45(G A D D 45)$ and as also as GADD45A's transcriptional corepressor during cell cycle $\mathrm{G} 2 / \mathrm{M}$ checkpoint in association with the zinc-finger protein 350 (ZNF350) [12, 13]. ZNF350, also known as zinc-finger and BRCA1-interacting protein with a Kruppel-associated box (KRAB) domain (ZBRK1), have been shown to be involved in the pathogenic developments of several human tumours, such as breast, colon, and cervical carcinogenesis [14-16]. In cervical cancer, increased ZNF350 gene expression is correlated with inhibition of growth and metastasis of cervical tumour cells, suggesting that ZNF350 could possibly be a tumour suppressor. A possible explanation is that the complex $\mathrm{CtIP}(\mathrm{CtTB}$ interacting protein)/ZNF350/ BRCA1 complex represses the expression of angiopoitin-1 (ANG1) and high-mobility group AT-hook 2 (HMGA2), which are commonly involved in the proliferation and vascular formation of breast tumours [17, 18]. ZN350 has been found to be a transcriptional repressor of $\mathrm{p} 21$ when associated with the KRAB domain-associated protein 1 and an increase of ZNF350 levels could result in sensitivity to DNA damage, possibly leading to carcinogenesis $[19,20]$.

In light of the recent evidence that ZNF350 gene variations is highly linked with breast cancer susceptibility and many previous studies have yielded conflicting results, we have conducted a thorough systematic review and meta analysis of the recent ZNF350 risk alleles and their associations with breast cancer.

\section{RESULTS}

\section{Study characteristics}

The search yielded a combined 176 references. Study selection process was shown in Figure 1. The final meta-analysis included a total of 4 articles of 5 data sets $[14,21-23]$. The 5 data sets included 6032 controls and 5824 breast cancer cases. The detailed characteristics of included studies are shown in Table 1.

\section{Meta-analysis results}

The main results of the meta-analysis were listed in Table 2. Overall there was no evidence of an association

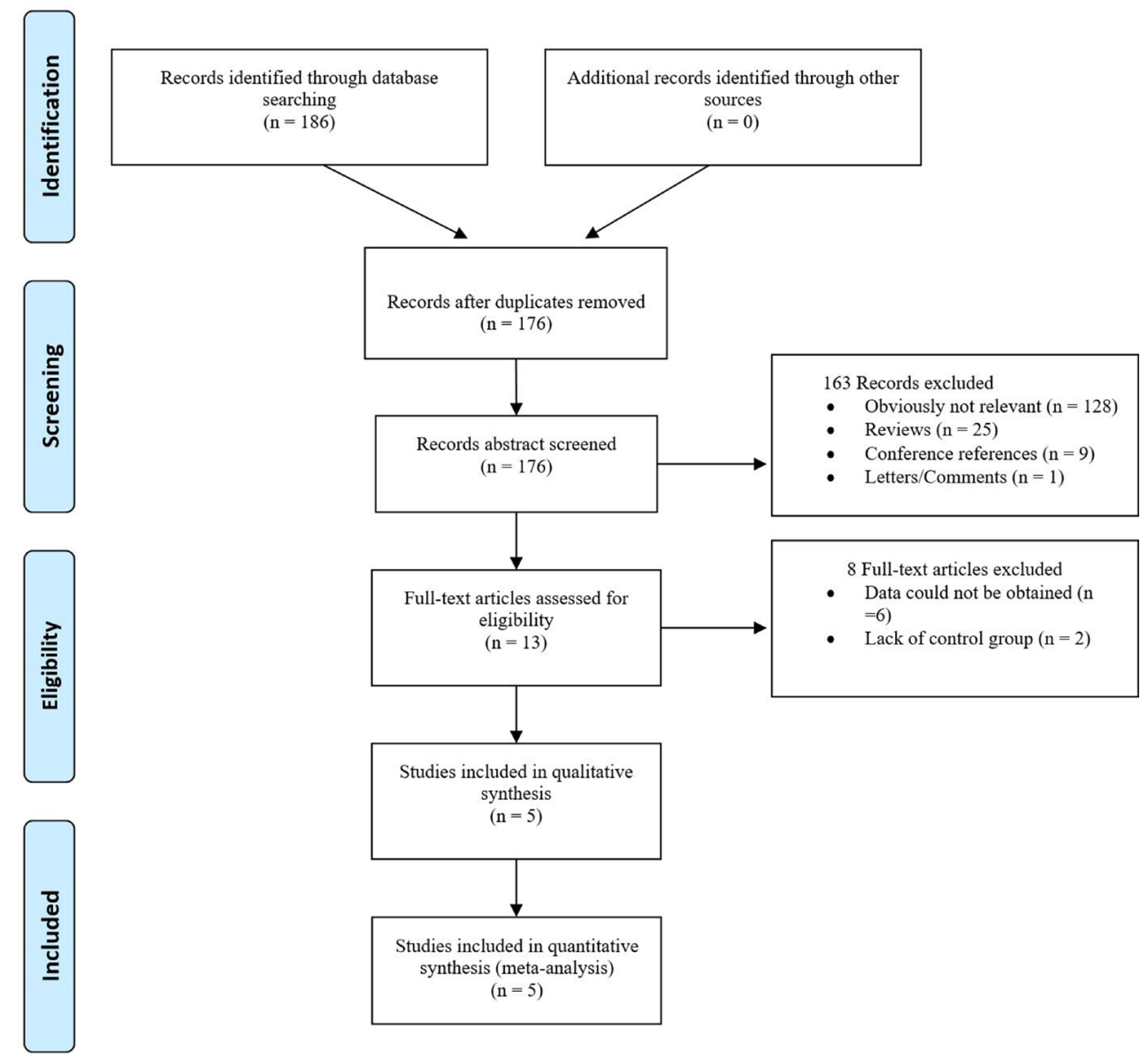

Figure 1: The PRISMA study selection diagram. 
Table 1: Characteristics of included studies

\begin{tabular}{|c|c|c|c|c|c|c|}
\hline Study & Year of publication & Genotyping Method & Control & Average age (Case/Control) & Number of (case/Control) & Newcastle-Ottawa \\
\hline Garcia & 2004 & Sequencing & Healthy Control & $\mathrm{NA} / \mathrm{NA}$ & $61 / 15$ & 6 \\
\hline Garcia-Closas (Polish) & 2006 & Sequencing & Healthy Control & $54 / \mathrm{NA}$ & $1978 / 2283$ & 7 \\
\hline Garcia-Closas (US) & 2006 & Sequencing & Healthy Control & 56/NA & $3181 / 3031$ & 7 \\
\hline Desjardin [19] & 2008 & Sequencing & Healthy Control & $48 / 46$ & $97 / 94$ & 6 \\
\hline Huo & 2008 & PCR-RFLP & Healthy Control & $52 / 51$ & $568 / 624$ & 6 \\
\hline
\end{tabular}

Table 2: Meta-analysis results

\begin{tabular}{|c|c|c|c|c|c|c|}
\hline \multirow{2}{*}{ Polymorphism } & \multirow{2}{*}{ Genetic Model } & \multirow{2}{*}{ Number of data sets } & \multirow{2}{*}{$\begin{array}{c}\text { Number of } \\
\text { cases/controls }\end{array}$} & \multicolumn{3}{|c|}{ Minor Allele } \\
\hline & & & & OR (95\% CI) & $\mathbf{P}(\mathrm{Z})$ & $\mathbf{P}(\mathbf{Q})$ \\
\hline \multirow{5}{*}{ Asp35Asp $(\mathrm{T}>\mathrm{C})$} & & \multirow[t]{5}{*}{5} & \multirow[t]{5}{*}{$5620 / 5519$} & & & \\
\hline & Allelic & & & $1.06(0.99-1.15)$ & 0.092 & 0.944 \\
\hline & Dominant & & & $1.02(0.88-1.18)$ & 0.814 & 0.838 \\
\hline & Recessive & & & $1.09(1.01-1.17)$ & 0.026 & 0.984 \\
\hline & Overdominant & & & $0.91(0.83-0.99)$ & 0.036 & 0.986 \\
\hline \multirow[t]{5}{*}{ Leu66Pro $(\mathrm{A}>\mathrm{G})$} & & \multirow[t]{5}{*}{4} & \multirow[t]{5}{*}{$5824 / 6032$} & & & \\
\hline & Allelic & & & $0.84(0.78-0.89)$ & 0.000 & 0.000 \\
\hline & Dominant & & & $0.57(0.47-0.69)$ & 0.000 & 0.002 \\
\hline & Recessive & & & $0.86(0.80-0.93)$ & 0.000 & 0.000 \\
\hline & Overdominant & & & $0.94(0.82-1.0)$ & 0.146 & 0.010 \\
\hline \multirow[t]{5}{*}{ Pro373Pro $(\mathrm{C}>\mathrm{A})$} & & \multirow[t]{5}{*}{3} & \multirow[t]{5}{*}{$5218 / 5060$} & & & \\
\hline & Allelic & & & $0.98(0.90-1.06)$ & 0.573 & 0.304 \\
\hline & Dominant & & & $0.90(0.68-1.18)$ & 0.449 & 0.893 \\
\hline & Recessive & & & $0.98(0.90-1.07)$ & 0.699 & 0.215 \\
\hline & Overdominant & & & $0.99(0.91-1.09)$ & 0.884 & 0.180 \\
\hline \multirow{5}{*}{ Ser472Pro $(C>A)$} & & \multirow[t]{5}{*}{3} & \multirow[t]{5}{*}{$5041 / 4917$} & & & \\
\hline & Allelic & & & $0.96(0.87-1.06)$ & 0.433 & 0.002 \\
\hline & Dominant & & & $0.10(0.04-0.23)$ & 0.000 & 0.119 \\
\hline & Recessive & & & $1.04(0.93-1.17)$ & 0.480 & 0.014 \\
\hline & Overdominant & & & $1.14(1.02-1.28)$ & 0.022 & 0.107 \\
\hline \multirow[t]{5}{*}{ Ser501Arg $(T>A)$} & & \multirow[t]{5}{*}{2} & \multirow[t]{5}{*}{$665 / 718$} & & & \\
\hline & Allelic & & & $0.95(0.79-1.15)$ & 0.612 & 0.168 \\
\hline & Dominant & & & $0.80(0.44-1.44)$ & 0.454 & 0.842 \\
\hline & Recessive & & & $1.21(1.02-1.44)$ & 0.026 & 0.017 \\
\hline & Overdominant & & & $1.00(0.80-1.25)$ & 0.977 & 0.079 \\
\hline
\end{tabular}

between the risk allele $\mathrm{C}$ and increased risks of breast cancer when four data sets were pooled together for the Asp35Asp ( $\mathrm{T}>\mathrm{C}$; rs4986773) polymorphism. The perallele OR of Pro using the random effects models was 1.06 [95\% CI: 0.99-1.15; P(Z) = 0.092; P(Q) = 0.944; Figure 2], although the data pooled OR was very close to being statistically significant. The recessive model does show that there is an association between the homozygous recessive and heterozygous and the risks of breast cancer $[\mathrm{OR}=1.09 ; 95 \% \mathrm{CI}: 1.01-1.17]$.

The $\mathrm{G}$ allele in the Leu66Pro $(\mathrm{A}>\mathrm{G})$ polymorphism has a protective effect to the risks of breast cancer $[\mathrm{OR}=0.84 ; 95 \%$ CI: 0.78-0.89]. The Leu66Pro polymorphism is also protective to the risks of breast cancer when using the the dominant, recessive, or the overdominant model (Figure 3).

The A allele Pro373Pro $(\mathrm{C}>\mathrm{A})$ polymorphism is not associated with risks of breast cancer using the allelic model $(\mathrm{OR}=0.98 ; 95 \% \mathrm{CI}: 0.90-1.06)$ or the dominant, recessive, or overdominant models (Figure 4). The Ser472Pro (C > A) polymorphism is no associated with the risks of vreat cancer using the allelic model $(\mathrm{OR}=0.96 ; 95 \% \mathrm{CI}: 0.87-1.06)$ or the recessive model $(\mathrm{OR}=1.04 ; 95 \% \mathrm{CI}=0.93-1.17)$. However, the homozygous genotypes is associated with the risks of breast cancer using the overdominant model $(\mathrm{OR}=1.14$; 95\% CI: 1.02-1.28; Figure 5).

The Arg allele of the Ser501Arg polymorphism is not associated with the breast cancer risks when using the 
A Allelic Model

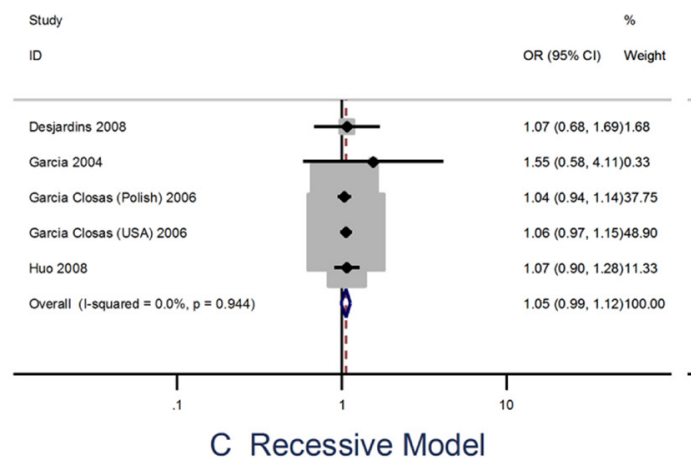

Study

ID

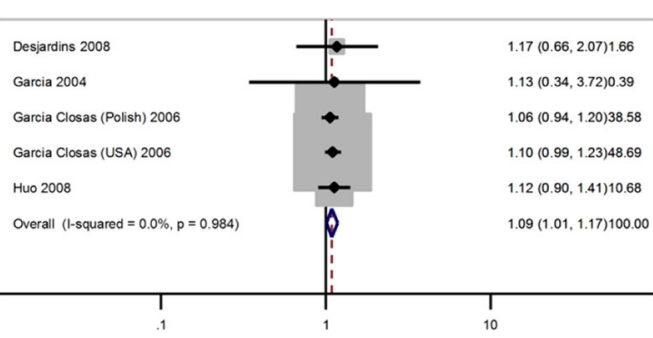

B Dominant Model
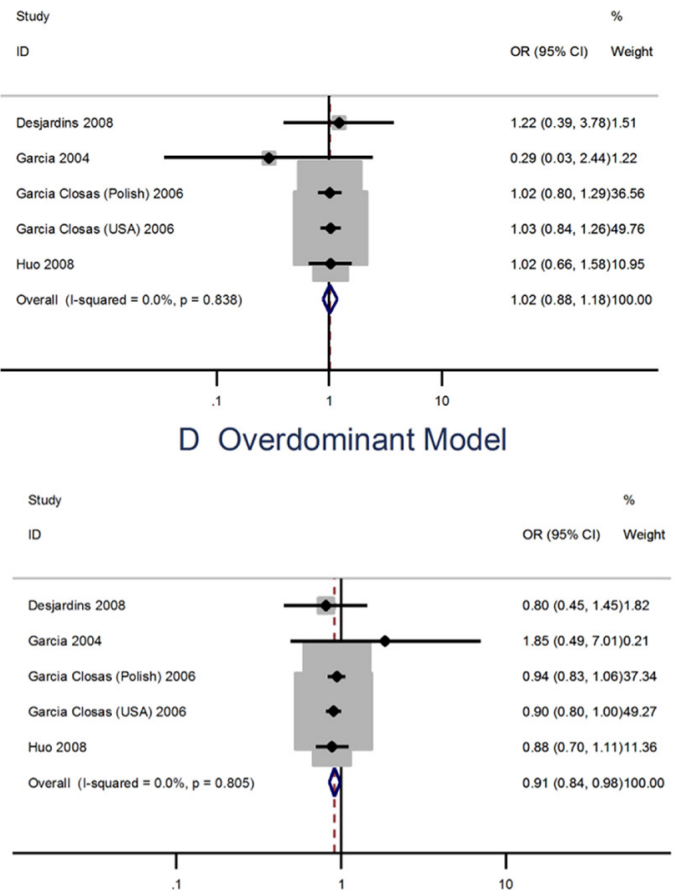

Figure 2: Meta analysis of the association between the Asp35Asp polymorphism and the risks of breast cancer using the (A) allelic, (B) dominant, (C) recessive, or (D) overdominant model.

A Allelic Model

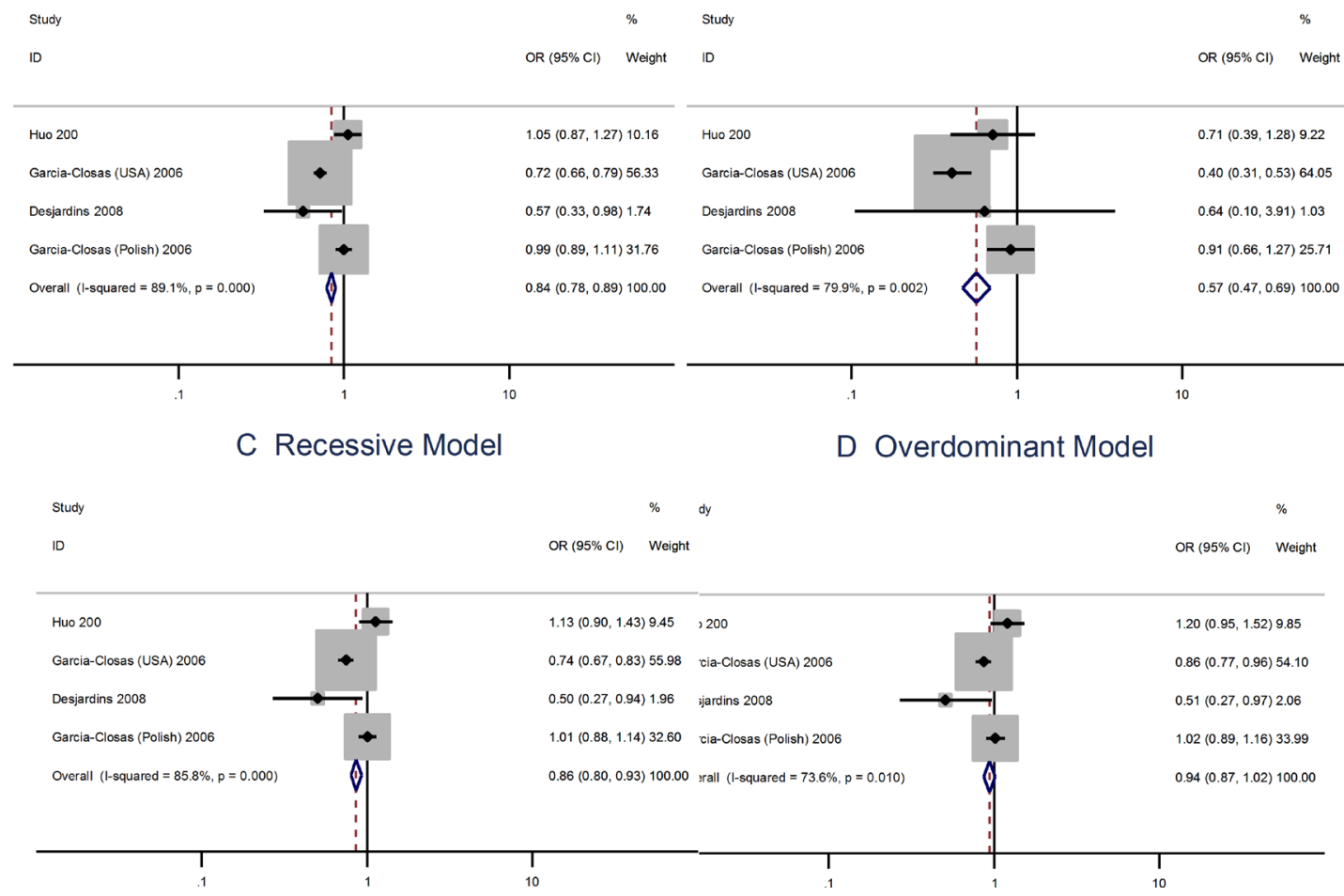

Figure 3: Meta analysis of the association between the Leu66Pro polymorphism and the risks of breast cancer using the (A) allelic, (B) dominant, (C) recessive, or (D) overdominant model. 


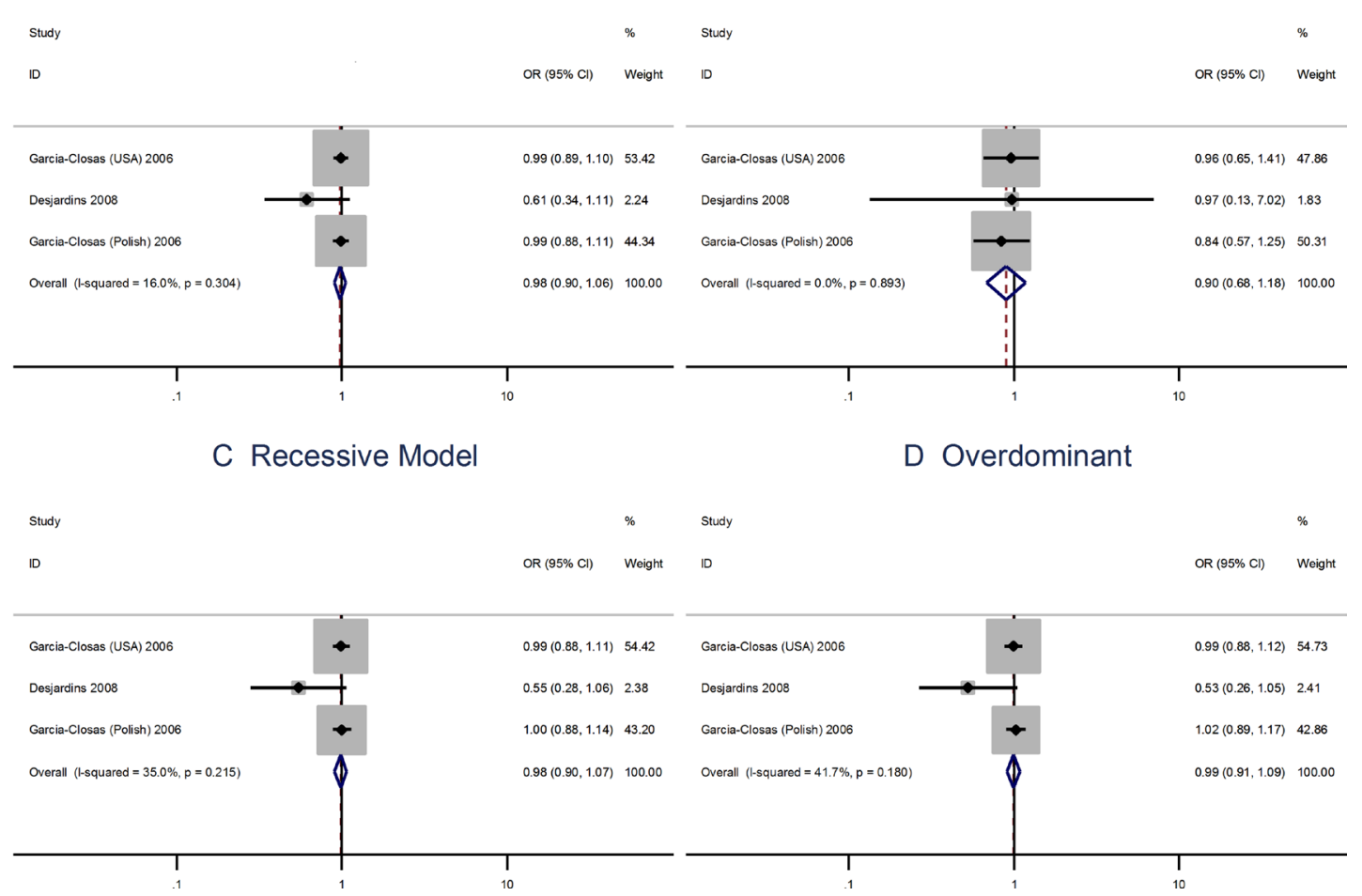

Figure 4: Meta analysis of the association between the Pro373Pro polymorphism and the risks of breast cancer using the (A) allelic, (B) dominant, (C) recessive, or (D) overdominant model.

A Allelic Model

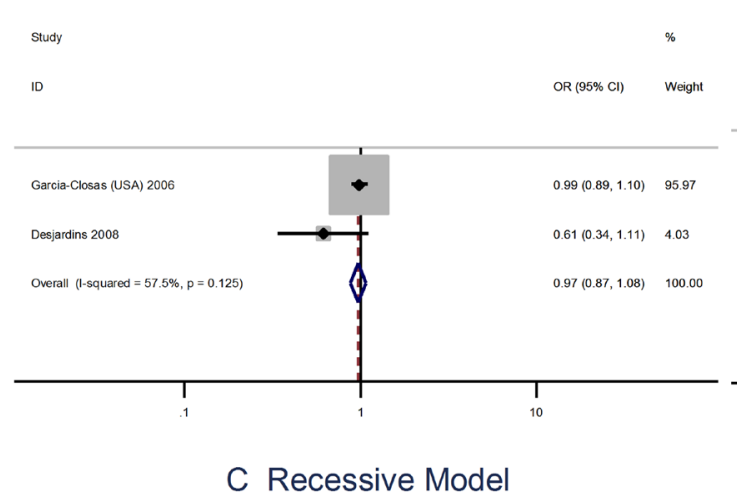

B Dominant Model

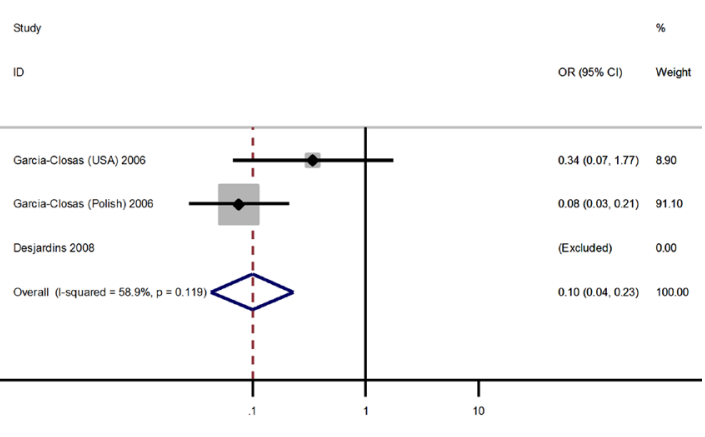

D Overdominant Model

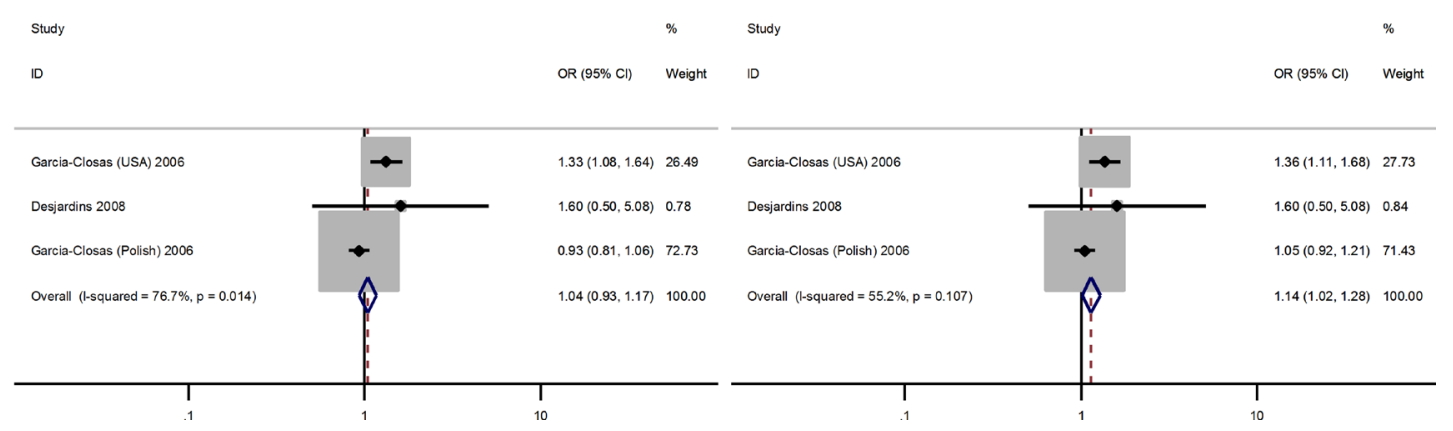

Figure 5: Meta analysis of the association between the Ser472Pro polymorphism and the risks of breast cancer using the (A) allelic, (B) dominant, (C) recessive, or (D) overdominant model. 
allelic model (OR $=0.95$; 95\% CI: 0.79-1.15). However, the Ser501Arg polymorphism is linked to breast cancer when applying the recessive model $(\mathrm{OR}=1.21 ; 95 \%$ CI: 1.02-1.44; Figure 6).

\section{Sensitivity analysis}

Sensitivity analyses using single-study omission demonstrated that this meta-analysis was stable. Statistical significance of the summary ORs was not modified. The data is not shown due to that the number of studies included is too low for some of the polymorphisms. However, a cumulative meta-analysis also shows that the results of this study are stable.

\section{Publication bias}

Begger's and Eggar's funnel plots were constructed using the standard error and compared against the OR of each study (Figure 7 and Figure 8). The plots do not suggest the existence of publication bias towards positive findings in smaller studies. Further, the Duval and Tweedie nonparametric "trim and fill" method was utilized to adjust for publication bias and its results did not show different conclusions (data not shown) [24]. Thus, this indicates that this meta-analysis is statistically robust.

\section{DISCUSSION}

Many genes involved in DNA repair and cell cycle have been linked with breast cancer [25-27], including the genes BRCA1 and BRCA2 which direct DNA double-stranded break by homologous recombination $[28,29]$. ZNF350 is a transcriptional repressor that has been suggested as a tumor suppressor due to its close corporation with BRCA1 and KAP-1 to silence DNA damage response genes.

ZNF350 is a 532 amino acid protein that contains an $\mathrm{N}$-terminal $\mathrm{A}+\mathrm{B}$ box domain, eight $\mathrm{C}_{2} \mathrm{H}_{2}$ zinc fingers in the centre, and a $\mathrm{C}$-terminal repression domain (CTRD) $[13,30]$. The CTRD undergoes tetrameric oligomerization that allows ZNF350 to selectively interact with BRCA1, specific histone deacetylases, and specific promoters $[31,32]$. ZNF has been found to repress the transcription of genes such as GADD45A [13], ANG1 [18], HMGA1 [17], p21 [20], MMP9 [16], FGF2 [33], and KAP1 [31].

The ZNF350 gene is mapped to chromosome 19 q13.4 and is near a cluster of other KRAB-Zinc finger proteins. SNPs in ZNF50 has been previously linked to the risks of developing breast cancer, although to conflicting results $[14,21-23]$.

We have conducted the first meta-analysis summarizing the evidence regarding the association

\section{A Allelic Model}

\section{B Dominant Model}

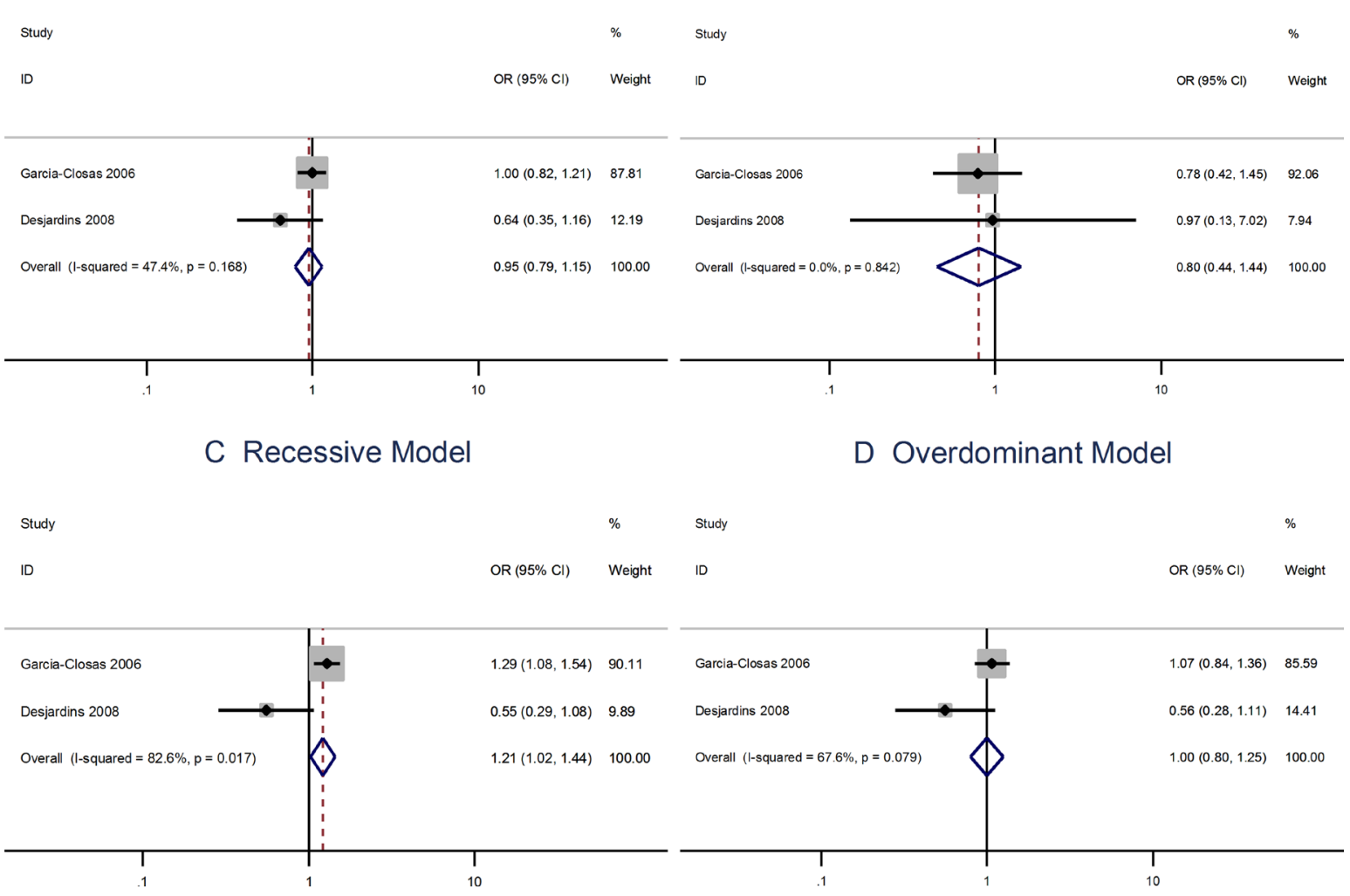

Figure 6: Meta analysis of the association between the Ser501Arg polymorphism and the risks of breast cancer using the (A) allelic, (B) dominant, (C) recessive, or (D) overdominant model. 
between the five ZNF350 SNPs and the risks of developing breast cancer. Our results suggest that the Leu66Pro polymorphism is mostly likely associated with modifying the risks of breast cancer, while patients with Asp35Asp and Ser501Arg SNPs have increased odds of breast cancer. Asp35Asp and Ser472Pro could be protective using the overdominant model.

Publication bias, the preferential publication of studies with positive results, is a significant problem in many meta-analyses. However, our meta-analysis also includes studies with negative conclusions. Furthermore, our funnel plots do not appear asymmetric, suggesting that publication bias is not a problem within our study.

Several limitations should be noted in interpreting the results of our meta-analysis. First, we were not able to adjust for potential confounding effects conferred by age, gender, lifestyle, and environmental factors due to the lack of individual data. Our results were based on unadjusted estimates - a more precise analysis could be conducted if all raw data related to the confounders were available.
A

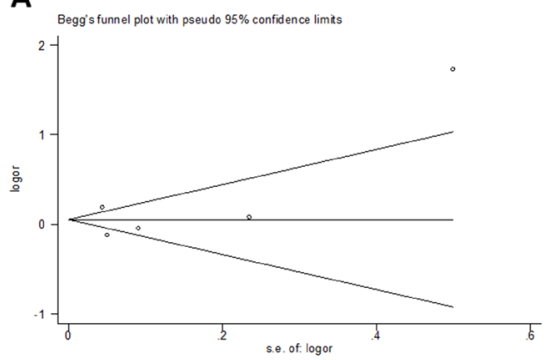

D

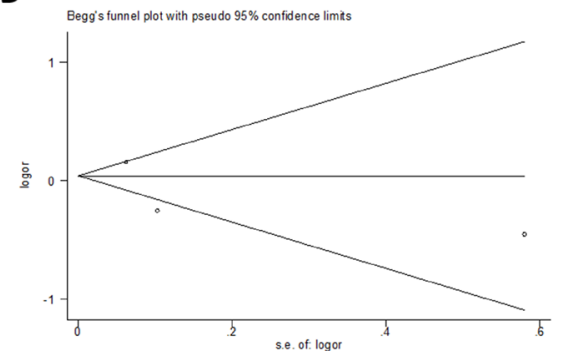

B

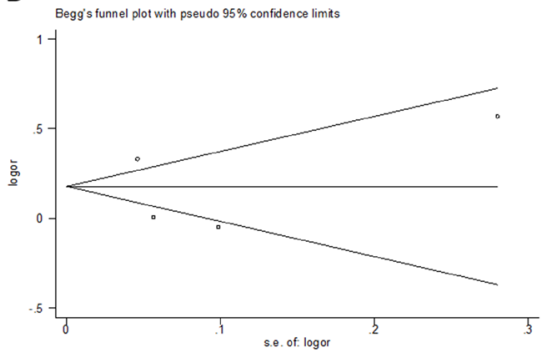

E

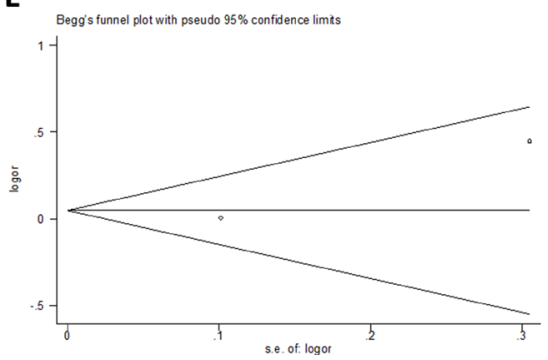

Figure 7: Begg's plot of the included studies for the (A) Asp35Asp, (B) Leu66Pro, (C) Pro373Pro, (D) Ser472Pro, and (E) Ser501Arg polymorphisms.
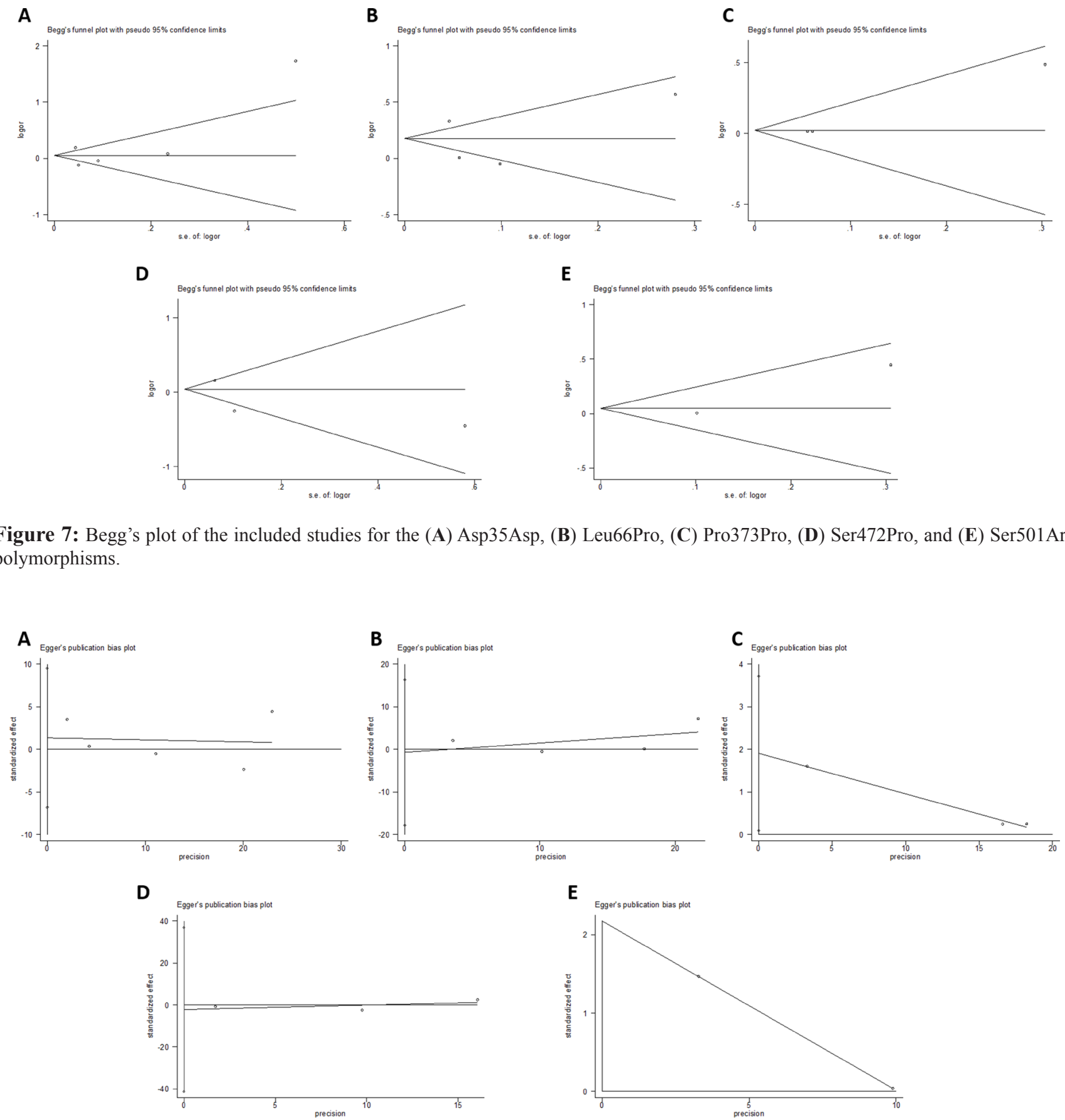

Figure 8: Egger's plot of the included studies for the (A) Asp35Asp, (B) Leu66Pro, (C) Pro373Pro, (D) Ser472Pro, and (E) Ser501Arg polymorphisms. 
The lack of important individual health data, such as body mass index (BMI), drug history, diet, and age, also forbid us from performing a more sensitive analysis.

Although the functional significances of the mutations studied in the current study is unknown, we postulate that mutations such as Leu66Pro have many important biological roles as it is found in the KRABdomain of the protein. In conclusion, the pooled results of our meta-analysis studying We propose to that both future large-scale clinical studies and functional studies are needed to elucidate the role to which ZNF350 modify the risks of breast cancer.

\section{MATERIALS AND METHODS}

\section{Search strategy and inclusion criteria}

We searched the literature hosted on PubMed, Web of Science, EMBASE, Ovid, Chinese National Knowledge Databases and WanFang with keywords related to breast cancer and the gene of interest (e.g. "zinc finger 350", "ZNF350", "zinc-finger and BRCA1-interacting protein with a KRAB domain 1", and "ZBRK1"). Genetic association studies published before May 2017 were retrieved and no earlier publication date limit was applied. The last search was performed on the May 1st, 2017. For each study screened, we checked their references to identify other relevant publications to the topic. The systematic search was conducted without any restrictions on the language used and the minimum number of patients required to be included. The study focused on human studies.

All retrieved study were screened and considered elgible if satisfying each point of the following criteria: 1) case-control or cohort study, 2) original papers containing independent trials, 3) confirmation of breast cancer, and 4) genotype distribution information of both the control and experimental group or odds ratio (OR) with its $95 \%$ confidence interval (CI) and $\mathrm{P}$ value. The major reasons for exclusion of studies were case-only studies, overlapping data, insufficient data for analyses, and review articles.

\section{Data extraction}

Data extraction was performed independently by two reviewers using a standard extraction form. All data were checked for internal consistency and disagreements were resolved through thorough discussion between all authors. If there were doubts about the result of studies, the corresponding author of the study of interest was contacted. For each study, the following were extracted from each article: first author's name, publication year, diagnostic criterion, definition and numbers of cases and controls, ethnicity of the study population, frequency of genotypes, genotyping method, source of controls, Hardy-Weinberg equilibrium (HWE), age, body-mass index (BMI). Studies with different ethnic groups within the same study were considered as individual studies for our analyses.

\section{Statistical analysis}

The association strength between the five ZNF350 polymorphisms and breast cancer was assessed by calculating OR with $95 \% \mathrm{CI}$.

The chi-square $\left(\chi^{2}\right)$ test was used to evaluate whether there is a significant deviation from HWE among the control subjects of the study. The per-allele OR of risk allele $\mathrm{T}$ was compared between cases and controls in each study. The ORs were pooled using both the randomeffects model (the DerSimonian and Laird method) and the fixed effects model (the Mantel-Haenszel method) as previously described $[34,35]$. The Woolf's method was used to calculate $95 \%$ CI [36]. The results of calculations using the random effects model were reported in this article because it takes into consideration the variation between studies.

Heterogeneity across individual studies was examined using Cochran's $\chi^{2} Q$ test [37]. $Q$ test was also performed to detect the heterogeneity within each subgroup. Publication bias was assessed using linear regression to measure funnel plot asymmetry on the natural logarithm of OR using Egger's method [38]. All statistical analysis was carried out with Stata Version 13.0 (Stata Corporation, College Station, Texas, USA. All $P$ values were for twosided analysis. Type I error rate was set at 0.05 .

\section{Abbreviations}

ANG1 = angiopoitin-1, BRCA1 = breast cancer 1 , $\mathrm{BMI}=$ body mass index, $\mathrm{CI}=$ confidence Interval, $\mathrm{CtIP}$ $=\mathrm{CtTB}$ interacting protein, GADD45A $=$ growth arrest and DNA damage gene 45, HWE = Hardy-Weinberg equilibrium, $\mathrm{KRAB}=$ Kruppel-associated box, $\mathrm{OR}=$ odds ratio, $\mathrm{ZNF} 350=$ zinc finger $350, \mathrm{ZBRK} 1=$ zinc-finger and BRCA1-interacting protein with a KRAB domain 1.

This work is supported by the Natural Science Foundation of Jiangsu Province in 2015 (BK20151261). The funders had no role in study design, data collection and analysis, decision to publish, or preparation of the manuscript.

\section{Author contributions}

Conceived and designed the experiments: YZ, LZ. Performed the experiments: YZ. Analyzed the data: YZ, LZ. Wrote the paper: YZ, LZ.

\section{CONFLICTS OF INTEREST}

We declare no conflicts of interest. 


\section{REFERENCES}

1. Hortobagyi GN, de la Garza Salazar J, Pritchard K, Amadori D, Haidinger R, Hudis C, Khaled H, Liu MC, Martin M, Namer M, O'Shaughnessy J, Shen ZZ, Albain KS. The global breast cancer burden: variations in epidemiology and survival. Clin Breast Cancer. 2005; 6:391-401.

2. Shibuya K, Mathers CD, Boschi-Pinto C, Lopez AD, Murray CL. Global and regional estimates of cancer mortality and incidence by site: II. Results for the global burden of disease 2000. BMC Cancer. 2002; 2:37.

3. Ries LG, Harkins D, Krapcho M, Mariotto A, Miller BA, Feuer EJ, Clegg LX, Eisner MP, Horner MJ, Howlader N. SEER cancer statistics review. 1975-2003. 2006.

4. Antoniou AC, Pharoah PP, McMullan G, Day NE, Ponder BJ, Easton D. Evidence for further breast cancer susceptibility genes in addition to BRCA1 and BRCA2 in a population-based study. Genet Epidemiol. 2001; 21:1-18.

5. Antoniou AC, Pharoah PD, Smith P, Easton DF. The BOADICEA model of genetic susceptibility to breast and ovarian cancer. Br J Cancer. 2004; 91:1580-90.

6. Couch FJ, DeShano ML, Blackwood MA, Calzone K, Stopfer J, Campeau L, Ganguly A, Rebbeck T, Weber BL. BRCA1 mutations in women attending clinics that evaluate the risk of breast cancer. N Engl J Med. 1997; 336:1409-15.

7. Thompson ME, Jensen RA, Obermiller PS, Page DL, Holt JT. Decreased expression of BRCA1 accelerates growth and is often present during sporadic breast cancer progression. Nat Genet. 1995; 9:444-50.

8. Miki Y, Swensen J, Shattuck-Eidens D, Futreal PA, Harshman K, Tavtigian S, Liu Q, Cochran C, Bennett LM, Ding W. A strong candidate for the breast and ovarian cancer susceptibility gene BRCA1. Science. 1994; 266:66-71.

9. Chen Y, Farmer AA, Chen CF, Jones DC, Chen PL, Lee WH. BRCA1 is a $220-\mathrm{kDa}$ nuclear phosphoprotein that is expressed and phosphorylated in a cell cycle-dependent manner. Cancer Res. 1996; 56:3168-72.

10. Cao L, Xu X, Bunting SF, Liu J, Wang RH, Cao LL, Wu JJ, Peng TN, Chen J, Nussenzweig A, Deng CX, Finkel T. A Selective Requirement for 53BP1 in the Biological Response to Genomic Instability Induced by Brcal Deficiency. Mol Cell. 2009; 35:534-41.

11. Hatchi E, Skourti-Stathaki K, Ventz S, Pinello L, Yen A, Kamieniarz-Gdula K, Dimitrov S, Pathania S, McKinney KM, Eaton ML, Kellis M, Hill SJ, Parmigiani G, et al. BRCA1 recruitment to transcriptional pause sites is required for R-loopdriven DNA damage repair. Mol Cell. 2015; 57:636-47.

12. Fan $\mathrm{W}$, Jin $\mathrm{S}$, Tong $\mathrm{T}$, Zhao H, Fan F, Antinore MJ, Rajasekaran B, Wu M, Zhan Q. BRCA1 regulates GADD45 through its interactions with the OCT-1 and CAAT motifs. J Biol Chem. American Society for Biochemistry and Molecular Biology. 2002; 277:8061-7.

13. Zheng L, Pan H, Li S, Flesken-Nikitin A, Chen PL, Boyer TG, Lee WH. Sequence-specific transcriptional corepressor function for BRCA1 through a novel zinc finger protein, ZBRK1. Mol Cell. 2000; 6:757-68.

14. Garcia V, Domínguez G, García JM, Silva J, Peña C, Silva JM, Carcereny E, Menendez J, España P, Bonilla F. Altered expression of the ZBRK1 gene in human breast carcinomas. J Pathol. 2004; 202:224-32.

15. Garcia V, García JM, Peña C, Silva J, Domínguez G, Rodríguez R, Maximiano C, Espinosa R, España P, Bonilla F. TheGADD45, ZBRK1 andBRCA1 pathway: quantitative analysis of mRNA expression in colon carcinomas. J Pathol. $2005 ; 206: 92-9$.

16. Lin LF, Chuang CH, Li CF, Liao CC, Cheng CP, Cheng TL, Shen MR, Tseng JT, Chang WC, Lee WH, Wang JM. ZBRK1 Acts as a Metastatic Suppressor by Directly Regulating MMP9 in Cervical Cancer. Cancer Res. 2010; 70:192-201.

17. Ahmed KM, Tsai CY, Lee WH. Derepression of HMGA2 via removal of ZBRK1/BRCA1/CtIP complex enhances mammary tumorigenesis. J Biol Chem. American Society for Biochemistry and Molecular Biology. 2010; 285:4464-71.

18. Furuta S, Wang JM, Wei S, Jeng YM, Jiang X, Gu B, Chen PL, Lee EH, Lee WH. Removal of BRCA1/CtIP/ZBRK1 repressor complex on ANG1 promoter leads to accelerated mammary tumor growth contributed by prominent vasculature. Cancer Cell. 2006; 10:13-24.

19. Madison DL, Lundblad JR. C-terminal binding protein and poly(ADP)ribose polymerase 1 contribute to repression of the p21waf1/cip1 promoter. Oncogene. 2010; 29:6027-39.

20. Lee YK, Thomas SN, Yang AJ, Ann DK. Doxorubicin down-regulates Kruppel-associated box domain-associated protein 1 sumoylation that relieves its transcription repression on $\mathrm{p} 21 \mathrm{WAF} 1 / \mathrm{CIP} 1$ in breast cancer MCF-7 cells. J Biol Chem. 2007; 282:1595-606.

21. García-Closas M, Egan KM, Newcomb PA, Brinton LA, Titus-Ernstoff L, Chanock S, Welch R, Lissowska J, Peplonska B, Szeszenia-Dabrowska N, Zatonski W, Bardin-Mikolajczak A, Struewing JP. Polymorphisms in DNA double-strand break repair genes and risk of breast cancer: Two population-based studies in USA and Poland, and meta-analyses. Hum Genet. 2006; 119:376-88.

22. Desjardins S, Belleau P, Labrie Y, Ouellette G, Bessette P, Chiquette J, Laframboise R, Lépine J, Lespérance B, Pichette R, Plante M, Durocher F, Simard J, et al. Genetic variants and haplotype analyses of the ZBRK1/ZNF350 gene in high-risk non BRCA1/2 French Canadian breast and ovarian cancer families. Int J Cancer. 2008; 122:108-16.

23. Huo X, Lu C, Huang X, Hu Z, Jin G, Ma H, Wang X, Qin J, Wang X, Shen H, Tang J. Polymorphisms in BRCA1, BRCA1-interacting genes and susceptibility of breast cancer in Chinese women. J Cancer Res Clin Oncol. 2009; 135:1569-75.

24. Duval S, Tweedie R. Trim and fill: A simple funnel-plotbased method of testing and adjusting for publication bias in meta-analysis. Biometrics. 2000; 56:455-63. 
25. Meindl A, Hellebrand H, Wiek C, Erven V, Wappenschmidt B, Niederacher D, Freund M, Lichtner P, Hartmann L, Schaal H, Ramser J, Honisch E, Kubisch C, et al. Germline mutations in breast and ovarian cancer pedigrees establish RAD51C as a human cancer susceptibility gene. Nat Genet. 2010; 42:410-4.

26. Turnbull C, Rahman N. Genetic predisposition to breast cancer: past, present, and future. Annu Rev Genomics Hum Genet. 2008; 9:321-45.

27. Farmer H, McCabe N, Lord CJ, Tutt AJ, Johnson DA, Richardson TB, Santarosa M, Dillon KJ, Hickson I, Knights C, Martin NB, Jackson SP, Smith GM, et al. Targeting the DNA repair defect in BRCA mutant cells as a therapeutic strategy. Nature. 2005; 434:917-21.

28. Tutt A, Ashworth A. The relationship between the roles of BRCA genes in DNA repair and cancer predisposition. Trends Mol Med. 2002; 8:571-6.

29. Guttmacher AE, Collins FS, Wooster R, Weber BL. Breast and Ovarian Cancer. N Engl J Med. 2003; 348:2339-47.

30. Ran Q, Wadhwa R, Bischof O, Venable S, Smith JR, Pereira-Smith OM. Characterization of a Novel Zinc Finger Gene with Increased Expression in Nondividing Normal Human Cells. Exp Cell Res. 2001; 263:156-62.

31. Tan W, Kim S, Boyer TG. Tetrameric oligomerization mediates transcriptional repression by the BRCA1- dependent Kruppel-associated box-zinc finger protein ZBRK1. J Biol Chem. 2004; 279:55153-60.

32. Tan W, Zheng L, Lee WH, Boyer TG. Functional dissection of transcription factor ZBRK1 reveals zinc fingers with dual roles in DNA-binding and BRCA1-dependent transcriptional repression. J Biol Chem. 2004; 279:6576-87.

33. Calderon MR, Verway M, Benslama RO, Birlea M, Bouttier M, Dimitrov V, Mader S, White JH. Ligand-dependent corepressor contributes to transcriptional repression by $\mathrm{C} 2 \mathrm{H} 2$ zinc-finger transcription factor ZBRK1 through association with KRAB-associated protein-1. Nucleic Acids Res. 2014; 42:7012-27.

34. DerSimonian R, Laird N. Meta-analysis in clinical trials. Control Clin Trials. 1986; 7:177-88.

35. Mantel N, Haenszel W. Statistical Aspects of the Analysis of Data From Retrospective Studies of Disease. J Natl Cancer Inst. 1959; 22:719-48.

36. Woolf B. On estimating the relation between blood group and disease. Ann Hum Genet. 1955; 19:251-3.

37. Cochran WG. The combination of estimates from different experiments. Biometrics. 1954; 10:101-29.

38. Egger M, Smith GD, Schneider M, Minder C. Bias in metaanalysis detected by a simple, graphical test. BMJ. 1997; 315:629-34. 